\title{
Quem ensina braille para alunos cegos? - A formação de professores em questão
}

\author{
Rosana Davanzo Batista* \\ Mateus Henrique do Amaral ${ }^{* *}$ \\ Maria Inês Bacellar Monteiro***
}

\section{Resumo}

Esse texto objetiva analisar as implicações das prescrições oficiais e currículos de formação de professores na (não) aprendizagem de braille por alunos cegos nas escolas regulares. Para isso, discute a legislação vigente e práticas relativas à formação inicial, especializações e cursos de curta duração. Conclui que a escassez de cursos formativos de professores de Educação Especial e a ausência de conteúdos sobre a educação de alunos com deficiência nos cursos de licenciatura indicam a falta de espaços que garantam o conhecimento do que é geral e particular para o ensino dos alunos cegos na educação escolar.

Palavras-chave: Educação especial; Formação de professores; Ensino do braille; Cegos.

\section{Who teaches Braille to blind students? - The teacher training in question}

\begin{abstract}
This paper aims at analyzing the implications of official prescriptions and teacher training curricula in (non) braille learning by blind students in regular schools. To do so, it discusses the current legislation and practices related to initial training, specializations and short courses. It concludes that the shortage of training courses for Special Education teachers and the absence of content about the education of students with disabilities in teaching courses indicate the lack of spaces that guarantee the knowledge of what is general and particular for the teaching of blind students in school education.
\end{abstract}

Keywords: Special education; Teacher training; Teaching braille; Blind people.

\section{¿Quién enseña braille para alumnos ciegos? - La formación de profesores en cuestión}

\section{Resumen}

Este texto tiene por objeto analizar las implicaciones de las prescripciones oficiales y los currículos de formación de profesores en el (no) aprendizaje del braille por alumnos ciegos en las escuelas regulares. Para ello, discute la legislación vigente y las prácticas relativas a la formación inicial, especializaciones y cursos de corta duración. Concluye que la escasez de cursos formativos de profesores de Educación Especial y la ausencia de contenidos sobre la educación de alumnos con discapacidad en los cursos de licenciatura indican la falta de espacios que garanticen el conocimiento de lo que es general y particular para la enseñanza de los alumnos ciegos en la educación escolar.

Palabras clave: Educación Especial; Formación de Profesores; Enseñanza de Braille; Personas ciegas.

\section{Introdução}

"Quem ensina braille para alunos cegos?" Tal questionamento, que integra o título deste texto, acompanha as inquietações de pesquisas que temos discutido e desenvolvido em torno da presença de estudantes cegos na escola regular. A partir de trabalhos de campo, da leitura de textos que abordam o assunto e de discussões em grupo de estudos, problematizamos a maneira pela qual as escolas regulares têm garantido, ou não, aos cegos a aprendizagem da linguagem escrita.

A política de Educação Especial vigente no
Brasil preconiza a educação regular como direito de todos e indica que os sistemas de ensino são responsáveis pelo "acesso aos espaços, aos recursos pedagógicos e à comunicação que favoreçam a promoção da aprendizagem e a valorização das diferenças, de forma a atender às necessidades educacionais de todos os estudantes" (BRASIL, 2008, p. 13). Ainda conforme a legislação, o aluno cego, assim como os demais alunos com deficiência, deve estar matriculado em salas de aula comuns do ensino regular e no Atendimento Educacional Especializado (AEE).

Muitos estudos têm ressaltado a importância

\footnotetext{
*Endereço Eletrônico: rosanadavanzo@yahoo.com.br

**Endereço Eletrônico: amaralmateush@gmail.com

****Endereço Eletrônico: moteirobim@gmail.com
} 
do ensino do braille para a alfabetização de alunos cegos (BATISTA, 1998; REILY, 2004; CAIADO, 2006; VILARONGA; CAIADO, 2013; BATISTA; MONTEIRO, 2014; BATISTA, 2018), destacando que, no contexto atual da educação inclusiva, estes alunos devem aprender o braille, de modo que seja possibilitada a apropriação do sistema de escrita e acesso a todos os conteúdos curriculares oferecidos aos demais alunos.

Contudo, ao olharmos para as práticas pedagógicas que acompanham as políticas da educação do aluno cego no Brasil, observamos muitas contradições. Vilaronga e Caiado (2013), em estudo sobre as trajetórias e expectativas de vida escolar de pessoas com deficiência visual que desejavam ingressar no ensino superior, ressaltam que uma das consequências das mudanças políticas da educação especial para os alunos cegos, que a partir de 1990 reconhece a educação especial como uma modalidade de ensino que deve ser oferecida preferencialmente na rede regular de ensino, foi a constatação, pelos próprios sujeitos cegos, da falta de preparo dos professores e da escola para possibilitar seu aprendizado.

A falta de formação dos professores das salas de aula comuns em relação às especificidades que caracterizam o ensino da pessoa com deficiência visual é, sem dúvida, um dos desafios enfrentados pelas escolas regulares no ensino do aluno cego. Outro fator problemático é a (falta de) construção de um trabalho colaborativo entre os professores das salas regulares e os das salas de Atendimento Educacional Especializado, prática que nem sempre ocorre por conta das condições de trabalho desses profissionais. Dentre outros motivos, o professor regular desconhece a atuação do AEE como um atendimento pedagógico.

Segundo Masini (2004, p. 30), "a escola passou a aceitar a criança com deficiência em seu quadro discente, sem, contudo, cuidar apropriadamente da formação de professores, permanecendo estes sem preparo para lidar com a criança diferente". A autora acrescenta que, além da falta de preparo do professor da sala de aula comum, o professor especializado "em sua formação, também não aprendeu a lidar com o professor do ensino comum. Assim, a entrada de crianças com deficiência na escola regular não contou com as condições necessárias para que o processo de inclusão pudesse ocorrer" (MASINI, 2004, p. 30).

Se considerarmos as políticas de inclusão incorporadas pela Lei de Diretrizes e Bases da Educação Nacional (LDB), vemos que está previsto no artigo 59, parágrafo III, a formação adequada de professores, "em nível médio ou superior, para atendimento especializado, bem como professores do ensino regular capacitados para a integração desses educandos nas classes comuns". No entanto, não é isso que encontramos nas escolas. Conforme apontado por Pimentel (2016, p. 15), apesar do reconhecimento dos avanços das políticas e da "garantia do acesso à escola comum pelos estudantes com deficiência, não se constatam, igualmente, mudanças das práticas educacionais no cotidiano das escolas".

Se os professores não estão preparados para receber alunos cegos em suas salas de aula comuns, acrescenta-se a isso o fato de que na modernidade a visão passa a ser considerada o principal órgão do conhecimento, deixando todos os outros órgãos em segundo plano (NOVAES, 2009). Nesse sentido, "os conteúdos escolares privilegiam a visualização em todas as áreas de conhecimento, de um universo permeado de símbolos gráficos, imagens, letras e números" (SILVA; SILVA; OLIVEIRA, 2014, p. 13).

No estudo realizado por Crochík (2016, p. 42), nota-se a queixa dos professores da sala de aula comum "de que não tinham formação suficiente para atender alunos com deficiências e o grande número de alunos em sala de aula". Assim, fica evidente que, nesse contexto, o aluno cego não tem assegurados seus direitos à educação escolar, já que o acesso desta população aos conhecimentos historicamente produzidos é negligenciado.

Outro desafio das escolas regulares em relação ao ensino do aluno cego diz respeito ao funcionamento do Atendimento Educacional Especializado. O AEE é hoje oferecido preferencialmente em salas de recursos multifuncionais, por professor especializado, no contraturno da matrícula no ensino regular e tem por função "identificar, elaborar e organizar recursos pedagógicos e de acessibilidade que eliminem as barreiras para a plena participação dos alunos, considerando suas necessidades específicas" (JESUS; VIEIRA, 2016, p. 69), ou seja, o atendimento suplementa e/ou complementa a formação dos alunos público-alvo da educação especial na escola regular. A concretização dessa prática, porém, nem sempre é uma tarefa fácil. Devemos considerar que o espaço para o diálogo entre o professor da sala de aula comum e o professor especializado da sala de AEE nem sempre é garantido. Segundo uma professora entrevistada por Jesus e Vieira (2016), 
Os professores ainda não se sentem capazes de trabalhar com os alunos. Em muitos casos, acham que se tem a sala de recursos é para lá que eles precisam ser encaminhados. Temos desafios na realização do planejamento. Isso faz com que o que é trabalhado na sala de aula comum encontre dificuldade de se relacionar com o atendimento educacional especializado. Ainda mais que estamos em turnos diferentes. Então como relacionar a sala de aula e a sala de recursos multifuncionais não está sendo fácil. (JESUS; VIEIRA, 2016, p. 78; grifo nosso).

Além da dificuldade de espaços para trocas entre docentes, uma crítica frequente dos professores das salas de aula comuns em relação aos do AEE é a de que estes últimos não se sentem responsáveis pelo ensino do aluno e acham que só precisam trabalhar a especificidade, como relatado por outra professora do estudo de Jesus e Vieira (2016), quando se refere ao modo como geralmente se colocam os professores da sala de recursos.

Precisam se colocar como aquele que também ensina. Não tem como só ficar dando dicas ou trabalhando de maneira isolada com o aluno. Tem professor que não pensa assim. Fala: "Eu só tenho que ensinar o braille ou o sorobã, porque sou professor de deficiência visual. A alfabetização é com o professor regente". Eu acho que não podemos mais pensar assim. Somos professores e temos que trabalhar juntos. (Professora entrevistada por JESUS; VIEIRA, 2016, p. 81).

$\mathrm{Na}$ fala apresentada acima, a professora explicita a ideia de dissociação entre a alfabetização e o ensino do braille, como se esses fossem processos totalmente distintos. Sem dúvida, essa é uma ideia que encontra raízes na incorporação das noções que fundamentam a legislação vigente, que destaca que o AEE deve "complementar ou suplementar a escolarização" (BRASIL, 2008, p. 6). Também pode indicar a compreensão do braille como um código, que precisa ser memorizado pelo aluno cego, desvinculado dos propósitos que lhe conferem sentido no meio social, o que é impróprio, uma vez que, "para dominar um sistema notacional, o indivíduo precisa desenvolver representações adequadas sobre como ele funciona, isto é, sobre suas propriedades" (GALVÃO; LEAL, 2005, p. 33).

Além do estudo de Jesus e Vieira (2016), há um amplo número de pesquisas recentes, inclusive revisões de literatura, que vêm indicando as dissociações entre o trabalho desenvolvido na sala de aula comum e no atendimento educacional especializado e o desconhecimento, por parte dos professores especializados, de suas reais atribuições na escola (BORGES; SANTOS, 2015; VICTOR; PILOTO, 2016).

Outro aspecto importante que revela a dificuldade de realização de um trabalho conjunto entre professores das salas de aula comuns e professores especializados das salas de AEE é que muitas vezes a escola frequentada pelo aluno cego não possui a sala de recursos disponível na mesma unidade e o aluno precisa deslocar-se no contraturno para outra escola. O deslocamento é disponibilizado pelo Estado, mas o diálogo entre os professores das diferentes escolas fica comprometido.

É importante ressaltar que a inclusão escolar deve garantir, além de vagas, condições de pleno desenvolvimento aos alunos que ingressam nas escolas, independentemente de suas condições e características pessoais, culturais e sociais. Nesse sentido, a inclusão dos alunos cegos em classe regular demanda um trabalho escolar de longo prazo, sendo necessário o preparo de toda a escola: alunos, funcionários e professores. Embora a LDB (BRASIL, 1996) e a Declaração de Salamanca (UNESCO, 1994) preconizem a educação inclusiva, na prática inexistem condições, tanto de trabalho quanto formativas, para que os professores possam desenvolver um trabalho educativo mais significativo com os alunos cegos.

A partir do exposto acima, este texto tem por objetivo analisar as implicações das prescrições oficiais e currículos de formação de professores na (não) aprendizagem de braille por alunos cegos nas escolas regulares, considerando a legislação de educação inclusiva vigente, as diretrizes e currículos das licenciaturas e a configuração formativa em educação especial na formação inicial, especializações e cursos de curta duração. Nessa direção, a discussão empreendida foi organizada em três seções, visando a explorar condicionantes que permitem compreender a restrição de acesso à linguagem escrita por alunos cegos nas escolas regulares. A primeira seção enfoca as proposições de documentos oficiais de educação inclusiva acerca da formação de professores para o trabalho com os alunos público-alvo da educação especial nas escolas regulares, dando prioridade à formação para a atuação com alunos cegos. $\mathrm{Na}$ segunda seção, exploramos as discussões acerca da educação inclusiva nos cursos de licenciatura, de uma forma geral, voltados para a formação de professores da sala regular. E, por fim, na terceira seção, adentramos a discussão sobre a formação de profissionais 
específicos, chamados de especializados, para trabalhar com alunos com deficiência na escola regular.

Antes de adentrarmos na discussão proposta, é importante considerarmos o recorte feito nesse estudo. A opção pela análise e discussão das prescrições e currículos de formação para a inclusão escolar de alunos cegos não significa a desconsideração das condições de trabalho docente, que estão totalmente associadas à formação, já que afetam a atratividade da carreira e as possibilidades de formação mais plena em serviço. Estudos identificam o modo como o nivelamento das condições de trabalho está vinculado a posições ideológicas que reiteram a "culpabilização individual do professor, considerado mal preparado pelos sistemas de avaliação, calcado no discurso de que a qualidade de ensino depende quase que exclusivamente do processo de formação do profissional" (NOGUEIRA, 2012, p. 1248-1249), descentralizando, portanto, a responsabilidade por condições mais dignas de trabalho nas escolas. Assim, ao enfocarmos a formação de professores, com o intuito de compreender as dificuldades de acesso e aprendizagem da linguagem escrita por alunos cegos na escola regular, entendemos que esta é uma das vias de articulação da problemática e não responsabilizamos tão somente as instituições formadoras, mas, sobretudo, o modo como as proposições oficiais, quando desveladas, dão indícios da falta de garantia e responsabilidade por condições apropriadas de aprendizagem para todos os alunos.

\section{O que dizem os documentos oficiais de educação inclusiva sobre a formação de professores para o ensino de alunos cegos}

Os movimentos internacionais para uma escola mais democrática e menos excludente começaram na década de 1970, opondo-se ao modelo de segregação da época, e influenciaram a política de Educação Especial do Brasil. Segundo Mendes (2006, p. 388), esses movimentos

conscientizaram e sensibilizaram a sociedade sobre os prejuízos da segregação e da marginalização de indivíduos de grupos com status minoritários, tornando a segregação sistemática de qualquer grupo ou criança uma prática intolerável. Tal contexto alicerçou uma espécie de base moral para a proposta de integração escolar, sob o argumento irrefutável de que todas as crianças com deficiências teriam o direito inalienável de participar de todos os programas e atividades cotidianas que eram acessíveis para as demais crianças.

Todavia, o avanço na legislação brasileira, propiciado pela influência dessa nova forma de olhar, não reflete toda a complexidade que envolve a educação da pessoa com deficiência. Conforme apontado por Caiado (2006, p. 27), há contradições que não podem ser resolvidas sem um destaque na política educacional, "uma vez que a pessoa deficiente nunca foi efetivamente contemplada pelas políticas sociais e educacionais e que nossa prática educacional em educação especial foi construída no paradigma da educação não-formal e segregada".

O marco legislativo pioneiro da inclusão da pessoa com deficiência no Brasil é a Constituição Federal, promulgada no dia 5 de outubro de 1988 (BRASIL, 1988), que afirma, no artigo 208, que o atendimento educacional especializado aos portadores de deficiência deve ocorrer preferencialmente na rede regular de ensino. O texto apresentado sofreu 25 emendas em dez anos de existência e, por consolidar várias conquistas de direitos, é conhecido como a "constituição cidadã". Caiado (2006, p. 9-10) aponta que, embora "forças conservadoras no Congresso tenham lutado contra o direito público de uma educação especial inclusiva no ensino regular, esse direito foi grafado como vitória das forças progressistas".

$\mathrm{O}$ reflexo dos movimentos internacionais sobre as políticas educacionais brasileiras reforçou cada vez mais a ideologia da educação inclusiva. Em 1990, em Jomtien, na Tailândia, foi realizada a Conferência Mundial sobre Educação para Todos. Nessa conferência, foi elaborado um documento (UNESCO, 1990) que declara a necessidade de concentrar esforços para atender às necessidades educacionais de alunos privados do direito de acesso, ingresso e permanência na escola, que deveriam nortear as bases dos planos decenais da educação, prioritariamente em países com altos índices populacionais. Ainda segundo o documento, a educação básica deve ser garantida a todos, como condição indispensável para que haja um bom desenvolvimento dos educandos.

Em junho de 1994, foi realizada na Espanha, na cidade de Salamanca, a Conferência Mundial sobre Necessidades Educacionais Especiais: Acesso e Qualidade, que produziu a Declaração de Salamanca (UNESCO, 1994), que reafirma o compromisso para com a educação para todos e reconhece a necessidade de educação para crianças, jovens e adultos com necessidades educacionais 
especiais dentro do sistema regular de ensino. Estiveram presentes nessa conferência representantes de 92 governos e 25 organizações internacionais. Segundo Caiado (2006, p. 19), o governo do Brasil não compareceu à reunião, mas "a Coordenadoria Nacional para Integração da Pessoa Portadora de Deficiência (Corde), vinculada à Secretaria Nacional de Direitos Humanos, do Ministério da Justiça, manifestou apoio, publicou e divulgou amplamente o documento aprovado". O informe final da conferência

reconhece a necessidade e a urgência de o ensino ministrado no sistema comum de educação ser para todas as crianças; proclama que a escola inclusiva proporciona uma educação efetiva à maioria das crianças e melhora a eficiência e, certamente, a relação custo-benefício de todo o sistema educativo e realça como uma das áreas prioritárias a preparação dos jovens com necessidades educativas especiais. (CAIADO, 2006, p. 19).

No Brasil, após oito anos de tramitação na Câmara dos Deputados e no Senado, a Nova Lei de Diretrizes e Bases da Educação Nacional, Lei n. 9.394/96, incorporou, em $1^{\circ}$ de janeiro de 1996, pela primeira vez, um capítulo (V) que se refere especificamente à educação especial. A nova LDB indica a responsabilidade do poder público em relação à educação do aluno com deficiência, a matrícula preferencial deste na rede regular de ensino e apoios especializados quando necessários.

A Resolução CNE/CEB n. 4, de 2 de outubro de 2009, que "institui diretrizes operacionais para o atendimento educacional especializado na educação básica, modalidade educação especial", acompanhando a tendência já apontada, define que

os sistemas de ensino devem matricular os alunos com deficiência, transtornos globais do desenvolvimento e altas habilidades/superdotação nas classes comuns do ensino regular e no Atendimento Educacional Especializado (AEE), ofertado em salas de recursos multifuncionais ou em centros de Atendimento Educacional Especializado da rede pública ou de instituições comunitárias, confessionais ou filantrópicas sem fins lucrativos. (BRASIL, 2009, p. 1).

A educação especial está, portanto, contemplada na legislação vigente. Todavia, no que se refere à formação de professores para o ensino de alunos com deficiência, a legislação deixa um espaço aberto.

O artigo $10^{\circ}$, inciso VII, da Resolução n. 4 do CNE/CEB, diz que

O projeto pedagógico da escola de ensino regular deve institucionalizar a oferta do AEE prevendo na sua organização $[\ldots]$ redes de apoio no âmbito da atuação profissional, da formação, do desenvolvimento da pesquisa, do acesso a recursos, serviços e equipamentos, entre outros que maximizem o AEE. (BRASIL, 2009, p. 2-3).

E, em seguida, no artigo $12^{\circ}$, temos breve referência à formação requerida dos professores para atuação no AEE, afirmando que "o professor deve ter formação inicial que o habilite para o exercício da docência e formação específica para a Educação Especial" (BRASIL, 2009, p. 3). Vê-se que a menção à formação aparece no documento, mas não há indicativo de como essa formação deverá se dar e qual formação é essa.

O modo genérico como a legislação trata as ações concretas para a formação dos professores para atuar na modalidade de ensino da Educação Especial também é visível no documento orientador para o atendimento educacional relativo especificamente a alunos com deficiência visual, elaborado em 2007 pela Secretaria de Educação Especial (SEESP), Secretaria de Educação a Distância (SEED) e Ministério da Educação (MEC), que trata sobre a Formação continuada a distância de professores para o atendimento educacional especializado (SÁ; CAMPOS; SILVA, 2007)². No item 5 desse documento, que trata de perguntas frequentes, as respostas sobre quem ensina braille ao aluno cego no ensino regular, bem como a que questiona se o professor que tem um aluno cego necessita conhecer o braille, demonstram como a formação dos professores para o ensino do braille nas escolas (salas regulares e no AEE) ainda é desvalorizada. Vejamos as respostas às perguntas 3 e 4 :

Quem ensina braille ao aluno cego no ensino regular? Quem estiver qualificado e disponível para este fim.

$O$ professor que tem um aluno cego necessita aprender o braille? O aprendizado do sistema braille certamente facilitará e enriquecerá o seu trabalho, pois será mais fácil e mais ágil acompanhar a evolução e os progressos do aluno sem a necessidade de intermediários, especialmente no que diz respeito à leitura e à escrita. (SÁ; CAMPOS; SILVA, 2007, p. 35).

A referência secundária à formação de 
professores na legislação tem permanecido nos documentos mais recentes. A lei $\mathrm{n}^{\circ} 13.146$, de 6 de julho de 2015, que institui a Lei Brasileira de Inclusão da Pessoa com Deficiência (Estatuto da Pessoa com Deficiência) em seu Capítulo IV, Art. 28., itens X e XI, incumbe ao poder público a tarefa de garantir, criar, desenvolver, implementar, incentivar, acompanhar e avaliar a

adoção de práticas pedagógicas inclusivas pelos programas de formação inicial e continuada de professores e oferta de formação continuada para o atendimento educacional especializado; formação e disponibilização de professores para o atendimento educacional especializado, de tradutores e intérpretes da Libras, de guias intérpretes e de profissionais de apoio. (BRASIL, 2015 , p. 8).

Contudo, não se observa nenhuma referência sobre como estas ações serão contempladas. A questão ainda é tratada com apontamentos genéricos.

Em relação especificamente à formação para o ensino do braille, o documento, em seu Capítulo II, Art. 73., afirma que

Caberá ao poder público, diretamente ou em parceria com organizações da sociedade civil, promover a capacitação de tradutores $\mathrm{e}$ intérpretes da Libras, de guias intérpretes e de profissionais habilitados em Braille, audiodescrição, estenotipia e legendagem. (BRASIL, 2015, p. 16; grifos nossos).

No entanto, não explicita como será garantida a capacitação necessária, o que traz alguns questionamentos: Essas ações têm sido contempladas? E, se sim, de qual forma?

O plano legal nos leva a refletir que parece existir um número muito maior de dúvidas e incertezas do que de ações concretas. Sem que se indique um espaço e se disponibilizem os recursos financeiros necessários, não há garantia de uma formação adequada de professores para o ensino do braille na perspectiva da educação inclusiva.

\section{A formação inicial de professores: o ensino de alunos cegos nos currículos dos cursos de licenciatura}

Conforme já apontamos no início desse texto, a falta de formação dos professores das salas de aula comuns em relação às especificidades que caracterizam o ensino da pessoa com deficiência visual e a ideia de que os professores do AEE só precisam trabalhar a especificidade do ensino em atividades que suplementam e/ou complementam a formação dos alunos sinalizam a necessidade de se criarem espaços concretos voltados à formação dos professores para a educação de alunos cegos.

Saviani (2009), ao analisar aspectos históricos e teóricos da formação de professores no Brasil, destaca que o lugar adequado para a formação específica de professores para atuar na Educação Especial seria o curso de Pedagogia. Entretanto, segundo ele, "a resolução CNE/CP 1, de 2006, que definiu as diretrizes curriculares nacionais para o curso de Pedagogia, toca na questão da Educação Especial de passagem e apenas duas vezes" (SAVIANI, 2009, p. 153), em dois dispositivos que tratam a questão de forma secundária, o artigo $5^{\circ}$, inciso X, e o artigo $8^{\circ}$, inciso III. Assim, o autor considera que

o quadro atual representa um retrocesso em relação ao período inaugurado em 1946 com a Lei Orgânica do Ensino Normal, [... uma vez que] essa legislação previa que os institutos de educação, além do ensino normal, ministrariam cursos de especialização para formar, entre outros, professores de Educação Especial" (SAVIANI, 2009, p. 153).

Ao analisar os currículos e ementas dos cursos de licenciatura em Pedagogia, Língua Portuguesa, Matemática e Ciências Biológicas, Gatti (2010, p. 1.359) ressalta que as licenciaturas "pela legislação, têm por objetivo formar professores para a educação básica: educação infantil (creche e pré-escola); ensino fundamental; ensino médio; ensino profissionalizante; educação de jovens e adultos; educação especial". A partir da análise de uma amostra composta por cursos de licenciatura presenciais (71 de Pedagogia, 32 de Língua Portuguesa, 31 de Matemática e 31 de Ciências Biológicas), distribuídos proporcionalmente em todo o país, a autora observou que as disciplinas relativas à Educação Especial correspondem a $3,8 \%$ do conjunto de disciplinas dos cursos de Pedagogia; $1 \%$ das disciplinas dos cursos de licenciatura em Letras; $0,5 \%$ das disciplinas de cursos de licenciatura em Matemática e $0,6 \%$ das disciplinas das licenciaturas em Ciências Biológicas (GATTI, 2010). Tais dados revelam o que Saviani (2009, p. 153) já havia afirmado em relação aos cursos de Pedagogia, ou seja, a ausência de "um espaço específico para cuidar da formação de professores para essa modalidade de ensino". 
A Resolução n. 2, de $1^{\circ}$ de julho de 2015, define as Diretrizes Curriculares Nacionais para a formação inicial em nível superior (cursos de licenciatura, cursos de formação pedagógica para graduados e cursos de segunda licenciatura) e para a formação continuada. Neste documento, a referência à formação de professores para a Educação Especial está expressa no Capítulo 1 (Art. 2, Art. 3 e em seu parágrafo $4^{\circ}$ ) e Capítulo V (Art. 13, em seu $2^{\circ}$ parágrafo, Art. $14,2^{\circ}$ parágrafo, Art. $15,3^{\circ}$ parágrafo).

Nos dois artigos do Capítulo 1, o texto menciona a Educação Especial dentre as várias condições que revelam a consciência da diversidade, ou seja: Educação de Jovens e Adultos, Educação Especial, Educação Profissional e Tecnológica, Educação do Campo, Educação Escolar Indígena, Educação a Distância e Educação Escolar Quilombola (Art. 2), assim como a relaciona ao desenvolvimento de profissionais para ocupar as funções de magistério na educação básica para os diferentes níveis de ensino (Art. 3).

Conforme já destacado por Saviani (2009), ao analisar a resolução $\mathrm{CNE} / \mathrm{CP} 1$, de 2006, que definiu as diretrizes curriculares nacionais para o curso de Pedagogia, a referência à orientação para a formação do professor em Educação Especial não é destacada em suas especificidades, colocando-a em meio a diferentes situações de diversidade ou níveis de escolaridade.

Como é possível inferir, não há nessas diretrizes menções específicas à educação dos alunos cegos, muito menos ao ensino de braille a estes, o que nos leva a mais questionamentos: Afinal, os professores do atendimento educacional especializado não são profissionais do ensino? Por que, então, sua formação não é contemplada nas Diretrizes? Quem deve ensinar braille ao aluno cego? Qual formação é necessária para esse profissional? Tais questionamentos nos remetem às questões que analisamos no tópico anterior, sobretudo no documento orientador do AEE (SÁ; CAMPOS; SILVA, 2007), que indica que o aluno cego deve aprender braille com alguém capacitado para o fim, que não necessita ser o professor especializado. Sendo assim, falamos de relações de ensino e aprendizagem e delegamos a tarefa a outro profissional? Este não deveria ser o professor? Por que isso não é contemplado nas políticas?

\footnotetext{
A formação de professores especializados e o ensino de braille para cegos: as licenciaturas, as especializações e os cursos de curta duração
}

Identificamos que os currículos das licenciaturas e as diretrizes de formação de professores, de modo geral, contemplam de forma imprecisa a formação para a Educação Especial/Inclusiva, o que - logicamente - influi na aprendizagem dos discentes cegos no cotidiano escolar. Na presente seção, partimos para a discussão sobre os cursos específicos em Educação Especial (licenciaturas, especializações e cursos de curta duração), de modo a compreender e inferir se/como a formação profissional para a educação de cegos, de modo mais específico voltado ao ensino de braille, é contemplada nesses cursos.

Em artigo recente sobre a inter-relação de políticas de educação superior com os contextos emergentes ${ }^{3}$ em três cursos específicos de educação especial -Licenciatura Plena (diurno, noturno e a distância) da Universidade Federal de Santa Maria, Corte e Mello (2018, p. 314) afirmam que "pouquíssimas Instituições de Educação Superior ofertam formação de licenciados em Educação Especial (Universidade Federal de Santa Maria e Universidade Federal de São Carlos)". Nos três cursos da UFSM, as autoras identificaram propostas que visam à formação de um profissional

capaz de identificar as possibilidades e necessidades dos alunos, que possa atuar nas redes de ensino em que as demandas de trabalho não são apenas de uma única deficiência, necessitando estabelecer uma interlocução entre os conhecimentos que são próprios com as situações do cotidiano escolar. (CORTE; MELLO, 2018, p. 314).

Segundo as autoras, "os contextos emergentes, considerando a expansão, a inclusão, a diversidade e a internacionalização, constituem-se desafios aos cursos de licenciatura" (CORTE; MELLO, 2018, p. 314). O curso de Educação Especial da UFSM, segundo elas, "se configura emergente devido às demandas sociais e as políticas públicas educacionais mundiais" (CORTE; MELLO, 2018, p. 325).

Com o objetivo de analisar os projetos pedagógicos e as grades curriculares de cursos de licenciatura em Educação Especial, Oliveira e Mendes (2017, p. 276) identificaram grande diversidade nas características dos cursos que, segundo elas, "reflete a ausência de diretrizes e bases norteadoras que forneçam uma identidade em comum aos cursos de formação inicial em educação especial". Uma análise criteriosa de dez cursos de licenciatura em Educação Especial existentes 
atualmente no Brasil permitiu às pesquisadoras afirmar que "o número de cursos de formação inicial em vigência está, provavelmente, aquém das necessidades do sistema educacional brasileiro" (OLIVEIRA; MENDES, 2017, p. 277), uma vez que os cursos, $75 \%$ deles oferecidos em universidades privadas, concentram-se exclusivamente nas regiões Sul e Sudeste, deixando descobertas as regiões Norte, Nordeste e Centro-Oeste; sem deixar de considerar que o número de professores formados nesses (poucos) cursos não é capaz de cobrir nem a totalidade de escolas presentes nessas regiões, que dirá em todo o país.

As autoras constataram também que os currículos dos cursos analisados mostram diferenças "sobre para qual público o professor a ser formado estará apto a fornecer os atendimentos educacionais especializados" (OLIVEIRA; MENDES, 2017, p. 275).

Especificamente em relação à formação de professores para alunos cegos, realizamos análise das grades curriculares e projetos pedagógicos dos cursos das duas universidades públicas brasileiras que oferecem cursos de licenciatura em Educação Especial (Universidade Federal de São Carlos e Universidade Federal de Santa Maria).

Em análise da grade curricular e programa de disciplinas do curso de Educação Especial Licenciatura Plena (Diurno ${ }^{4}$ ) da Universidade Federal de Santa Maria (CURSO 633, [s.d.]), constatamos uma única referência específica ao ensino de alunos com deficiência visual. Ela surge na disciplina complementar Tópicos Específicos em Educação Especial II, com carga horária de 60 horas, que apresenta, dentre outros objetivos mais gerais relacionados aos transtornos globais de desenvolvimento e às pessoas com déficit cognitivo, "Conhecer, definir e diferenciar a deficiência visual [...] Planejar estratégias pedagógicas para alunos com transtornos globais do desenvolvimento, deficiência visual e déficit cognitivo" (PORTAL, [s.d.]).

Embora a grade curricular e o ementário de disciplinas deste curso deem relevância à formação de professores, com disciplinas com conteúdo específico para o ensino de alunos surdos (ensino de Libras e estágio supervisionado/surdez, avaliação de processos culturais na educação de surdos, desenvolvimento do aluno surdo, ensino de língua portuguesa para surdos etc.), com déficit cognitivo, autismo e transtornos globais de desenvolvimento, não destacam um espaço específico para a formação de professores para o ensino do braille e de conteúdos peculiares relativos à educação dos alunos cegos. Ressalta-se que isto está em conformidade com o perfil do profissional que o curso se propõe a formar, que explicita que "Como professor de Educação Especial o diplomado deverá ter habilidades para atuar com alunos que apresentam dificuldades acentuadas de aprendizagem, relacionadas ou não ao déficit cognitivo, problemas de aprendizagem e alunos surdos" (CURSO 633, [s.d.]).

Segundo Oliveira e Mendes (2017, p. 275), "o curso da UFSM - noturno tem disciplinas que abordam as deficiências (visual, auditiva e intelectual), altas habilidades/ superdotação e TGD, com exceção da categoria deficiência física".

$\mathrm{O}$ projeto pedagógico do curso de Licenciatura em Educação Especial da Universidade Federal de São Carlos prevê:

disciplinas obrigatórias de caráter teórico e prático voltadas à formação do licenciando em Educação Especial, em consonância com a Política Nacional de Educação Especial na Perspectiva da Educação Inclusiva (BRASIL, 2008), de forma a garantir atendimento educacional de qualidade para alunos com deficiência intelectual, deficiência auditiva, deficiência física, deficiência visual, deficiência múltipla, surdocegueira, altas habilidades/superdotação e transtornos globais do desenvolvimento, nos diferentes níveis e modalidades de ensino, conforme recomendam os aportes legais (PROJETO POLÍTICOPEDAGÓGICO, 2012, p. 42; grifo nosso).

Em sua matriz curricular, identificamos uma disciplina específica (Procedimentos de Ensino em Educação Especial: Deficiência Visual), obrigatória, teórica, com um total de 60 horas, direcionada para a educação de alunos cegos, que tem por objetivos "Refletir sobre o trabalho pedagógico desenvolvido junto a alunos com deficiência visual. Analisar propostas de atuação na área" (PROJETO POLÍTICO-PEDAGÓGICO, 2012, p. 101). A ementa refere-se ao estudo histórico do conceito de deficiência visual e introdução a procedimentos de ensino nas "áreas de alfabetização (Sistema Braille/Sorobã), atividades de vida diária e programas de orientação e mobilidade" (PROJETO POLÍTICO-PEDAGÓGICO, 2012, p. 101), além de prever uma reflexão sobre a educação de pessoas cegas e com baixa visão.

Observamos também uma disciplina optativa específica, teórica, também com carga horária de 60 horas, voltada para o domínio do uso do sistema braille. A ementa da disciplina propõe a

reflexão sobre as abordagens e as tendências da 
educação do deficiente visual em direção a uma prática transformadora que possibilite a construção do conhecimento e a participação deste alunado na escola, na família e na sociedade. Caracterização dos aspectos teóricos e práticos do Sistema Braille. (PROJETO POLÍTICO-PEDAGÓGICO, 2012, p. 117).

Se considerarmos o crescente aumento de matrículas de alunos com deficiência visual, apontado no estudo realizado por Meletti e Bueno (2011, p. 380), a partir de análise de dados divulgados pelo Inep/Brasil, no período de 19772006, temos que de 6.500 matrículas no ensino regular, em 1998, passamos a 50 mil, em 2006, o que aponta para a necessidade de profissionais preparados para o ensino desses alunos nas salas de aula regulares e nos serviços especializados (AEE).

Já vimos que os cursos de Licenciatura em Pedagogia, Língua Portuguesa, Matemática, Ciências Biológicas (GATTI, 2010) apresentam conteúdos mínimos sobre a educação de alunos com deficiência e, portanto, não garantem uma formação adequada aos futuros professores de alunos cegos. Por outro lado, os cursos de Licenciatura em Educação Especial oferecidos nas duas únicas universidades identificadas (UFSM e UFSCar) não são suficientes para garantir oferta e formação em um país com a área geográfica do tamanho do Brasil, com mais de 207 milhões de habitantes (BRASIL, 2017). O censo demográfico de 2010, do Instituto Brasileiro de Geografia e Estatística (CENSO, 2010) aponta que 6,5 milhões de brasileiros possuem deficiência visual severa: 506 mil têm perda total da visão $(0,3 \%)$ e 6 milhões têm grande dificuldade para enxergar $(3,2 \%)$.

Alguns cursos de especialização e de curta duração (pós-graduação lato sensu) também são responsáveis pela formação de professores para o ensino de alunos com deficiência.

Especificamente para a educação dos alunos cegos, o Instituto Benjamin Constant (IBC), localizado no Rio de Janeiro, oferece oficinas e cursos de capacitação na área da deficiência visual, nas modalidades presencial e a distância. A carga horária dos cursos geralmente corresponde a 40 horas. Em 2018, foram divulgados, na página do IBC, 46 cursos presenciais, com o oferecimento de programas e conteúdo específico para cada curso, englobando mobilidade, alfabetização pelo sistema braille, técnicas de leitura em braille, audiodescrição, programas de informática, entre outros (CURSOS, 2018). Também estão anunciados, na página do IBC, seis cursos na modalidade a distância, com conteúdo de alfabetização em braille (dois cursos), programas de informática (dois cursos), acessibilidade e elaboração de gráficos táteis.

A Fundação Dorina Nowill, organização sem fins lucrativos e de caráter filantrópico, referência no trabalho de inclusão de pessoas com deficiência visual, criada em 1946, na cidade de São Paulo, também oferece cursos e palestras "para aproximar o tema da deficiência dos mais diversos públicos e da comunidade" (FUNDAÇÃO DORINA, [s.d.]). No momento da escrita deste artigo, a agenda de cursos oferecidos ainda não tinha sido noticiada na página da Fundação.

Cursos de braille de curta duração são oferecidos por diversas instituições privadas, geralmente na modalidade de ensino online, com carga horária que varia de 60 a 180 horas. Será que, em tão curto tempo, há uma formação voltada para o ensino dos alunos cegos? Ou se acredita que o simples conhecimento do sistema é suficiente para ensiná-lo?

\section{Os desafios para a formação de professores: políticas públicas e o trabalho concreto na sala de aula}

A formação inicial de professores para o ensino de alunos cegos mostra que ainda temos grandes desafios a enfrentar. Refletir sobre o trabalho do professor na educação destes alunos aponta para a necessidade de olharmos para além do que vem sendo realizado no contexto do cotidiano escolar, considerando as prescrições e currículos da formação tanto dos professores que irão atuar nas salas de aula comuns como daqueles que serão os professores das salas de AEE. A falta de uma formação específica do professor, conforme já apontado por Jesus e Vieira (2016, p. 80), "reduz a complexidade do processo ensino-aprendizagem do estudante com deficiência a uma discussão didática, como se tudo se resumisse a uma questão de ter uma técnica sobre como ensinar". Não se pode desconsiderar a importância do conhecimento científico, que em nossa sociedade está sob a responsabilidade da escola.

Vimos aqui como ainda é precária a formação de professores para o ensino de alunos cegos e, de modo mais específico, para o ensino de braille. A escassez de cursos para a formação inicial de professores de Educação Especial e a ausência de conteúdos curriculares sobre a educação de alunos com deficiência nos cursos de licenciatura (Pedagogia e demais cursos para formação de professores) mostra a falta de espaços específicos 
para cuidar da formação dos professores, e para garantir que eles conheçam o que é geral e o que é particular para o ensino de seus alunos. Se os professores não tiverem experiências concretas (teóricas e práticas) em seus cursos de formação, como poderão ensinar a seus alunos cegos?

Identificamos a necessidade de diretrizes curriculares específicas para os cursos de Educação Especial que contemplem as peculiaridades e os processos de desenvolvimento nas diversas deficiências. Esses cursos precisam expandir-se de modo a formar professores para atuar no AEE em todas as regiões do país. Para que essa formação não fique restrita a esforços individuais e propostas localizadas, é preciso que o poder público se responsabilize pela formação de professores especializados e, a partir de condições melhores de trabalho e remuneração, atraia um número maior de indivíduos para o magistério.

Além da formação do professor especializado, é necessário refletir sobre como os cursos de Pedagogia e demais licenciaturas formam seus professores que atuarão com alunos com deficiências em suas salas de aula regulares.

$\mathrm{O}$ aluno cego, assim como aquele que enxerga, desenvolve-se a partir das relações sociais significativas, que se constituem no coletivo (plano social) e são internalizadas (plano individual), permitindo a apropriação de novos conhecimentos, num processo dinâmico e dialético, mas é preciso considerar as peculiaridades para que se possa investir nas possibilidades emergentes. Conforme apontado por Vigotski (1997, p. 77, grifo do autor) ${ }^{5}$, "um ponto do sistema Braille fez mais pelos cegos do que milhares de filantropos; a possibilidade de ler e escrever se tornou mais importante do que "o sexto sentido' e a acuidade do toque e da audição" ou seja, o braille garante ao cego a introdução no universo simbólico da leitura e da escrita.

Não conhecer as características específicas e as necessidades de seus alunos cegos pode levar a uma ação baseada no senso comum, como entender o braille como um instrumento que substitui a grafia à tinta e que, portanto, pode ser aprendido a partir da memorização dos pontos correspondentes do alfabeto. $\mathrm{O}$ professor precisa saber que o braille faz parte da alfabetização do aluno cego e que aprender a ler e a escrever permite-lhe alcançar níveis mais complexos de desenvolvimento.

Mesmo considerando que o professor não é o único responsável (e nem o principal) pelo cumprimento das metas atuais das políticas educacionais, ele é, sem dúvida, central para o desenvolvimento de todos os seus alunos, incluindo aí o aluno cego. Se ele não tiver experiências formativas suficientes e suporte pedagógico (humano e material) para ensinar a seus alunos, não poderá lidar com as novas demandas de trabalho, nem reconhecer a realidade concreta na qual atua, de modo a lutar por condições de trabalho mais dignas, que permitam fazer da escola pública um contexto efetivo de formação humana. Por fim, como salienta Saviani (2009, p. 153), se não cuidarmos da formação de professores "de nada adiantarão as reiteradas proclamações referentes às virtudes da educação inclusiva que povoam os documentos oficiais e boa parte da literatura educacional nos dias de hoje".

\section{Notas}

1 São considerados alunos público-alvo da educação especial aqueles com deficiência, transtornos globais do desenvolvimento e altas habilidades/superdotação (BRASIL, 2008; 2009).

2 Iniciado em 2003, o Programa educação inclusiva: direito à diversidade foi uma ação proposta em âmbito nacional que tinha por objetivo, por meio de representantes de munícipios-polo em ações multiplicadoras, apoiar a formação de gestores e educadores, a fim de transformar os sistemas educacionais brasileiros em sistemas educacionais inclusivos. No âmbito desse programa, publicou-se uma série de diretrizes, materiais e documentos. Entre essas publicações, o título referenciado Atendimento educacional especializado deficiência visual, junto com outros quatro (AEE Orientações gerais e educação a distância; AEE Pessoa com surdez; AEE - Deficiência física; e AEE - Deficiência mental), integra um materialbase elaborado para o curso de aperfeiçoamento de professores para o Atendimento Educacional Especializado, promovido pela extinta Secretaria de Educação Especial e Secretaria de Educação a Distância, em ação conjunta com a Universidade Federal do Ceará (UFC). Estima-se, a partir de informações disponíveis na página da UFC (UFC VAI FORMAR, s.d.), que em 2007 foram formados 1.178 professores de 120 municípios e, em 2008, mais de 2.145, de 600 municípios. A referência a esse documento como orientador é por ser ele o único relacionado ao Atendimento Educacional Especializado de alunos cegos disponibilizado na aba de Educação Especial da Secretaria de Educação Continuada, Alfabetização, Diversidade e Inclusão - SECADI/MEC, 
constituindo-se o único documento específico de referência e consulta disponibilizado pelo Ministério da Educação relacionado a esse tipo de atendimento pedagógico (UFC VAI FORMAR, s.d.).

3 Segundo as autoras, contextos emergentes referemse às configurações em construção na educação superior que convivem em tensões com concepções preexistentes.

4 Não encontramos os projetos político-pedagógicos e grades curriculares online dos cursos nas modalidades noturno e EAD desta instituição.

5 "un punto del sistema Braille ha hecho más por los ciegos que miles de filántropos; la posibilidad de leer y escribir ha resultado ser más importante que 'el sexto sentido' y la agudeza del tacto y del oído" (VIGOTSKI, 1995, p. 77).

\section{Referências}

BATISTA, C. G. Crianças com deficiência visual: como favorecer sua escolarização? Temas em Psicologia, v. 6, n. 3, p. 217-229, 1998.

BATISTA, R. D. O processo de alfabetização de alunos cegos e o movimento da desbrailização. 2018. 81f. Tese (Doutorado em Educação) Programa de Pós-Graduação em Educação, Universidade Metodista de Piracicaba, Piracicaba, SP.

BATISTA, R. D.; MONTEIRO, M. I. B. O Braille e o material digitalizado no processo de ensino: aprendizagem da leitura e da escrita de alunos cegos. In: MONTEIRO, M. I. B.; FREITAS, A. P. de; CAMARGO, E. A. A. (Orgs.). Relações de ensino na perspectiva inclusiva: alunos e professores no contexto escolar. Araraquara, SP: Junqueira\&Marin, 2014, p. 249-268.

BORGES, C. S.; SANTOS, L. N. Atendimento educacional especializado: o que diz a literatura? In: JESUS, D. M. de; VICTOR, S. L.; GONÇALVES, A. F. S. (Orgs.). Formação, práticas pedagógicas e inclusão escolar no Observatório Estadual de Educação Especial. São Carlos: Marquezine \& Manzini/ABPEE, 2015. p. 81-90.

BRASIL. Constituição da República Federativa do Brasil de 1988. 1988. Disponível em:

<http://www.planalto.gov.br/ccivil_03/constituicao/ constituicao.htm>. Acesso em: 15 mai. 2018.

. Ministério de Educação e Cultura. Lei n. 9.394 de 20 de dezembro de 1996. Estabelece as diretrizes e bases da educação nacional. Diário Oficial da União, Brasília, 1996. Disponível em: <http://www.mec.gov.br/legis/pdf/lei9394>. Acesso em: 26 abr. 2018.

. MEC/CNE/CP. Resolução 1, de 15 de maio de 2006. Disponível em:

<http://portal.mec.gov.br/cne/arquivos/pdf/rcp01_0 6.pdf $>$. Acesso em: 05 de junho de 2018.

\section{. MEC/SECADI. Política nacional de}

educação especial na perspectiva da educação inclusiva. 2008. Disponível em:

$<$ http://portal.mec.gov.br/index.php?option=com_d ocman\&view=download\&alias $=16690$-politicanacional-de-educacao-especial-na-perspectiva-daeducacao-inclusiva-05122014\&Itemid=30192 > . Acesso em: 26 nov. 2017.

MEC/CNE/CEB. Resolução n. 4, de 2 de outubro de 2009. Institui diretrizes operacionais para o atendimento educacional especializado na educação básica, modalidade educação especial. Diário Oficial da União, Brasília, 5 de outubro de 2009, Seção 1, p. 17. Disponível em:

<http://portal.mec.gov.br/dmdocuments/rceb004_09 .pdf>. Acesso em: 24 nov. 2017.

. Ministério da Educação. Conselho

Nacional de Educação. Resolução n. 2, julho de 2015. Diretrizes Curriculares Nacionais para a formação inicial em nível superior (cursos de licenciatura, cursos de formação pedagógica para graduados e cursos de segunda licenciatura) e para a formação continuada. Disponível em:

$<$ http://den.prograd.ufsc.br/files/2016/07/2.7.Diretri zesLicenciatura2015_ResolucaoCNECP2_2015.pdf >. Acesso em: 05 jun. 2018.

. Lei n. 13.146, de 6 de julho de 2015.

Institui a Lei Brasileira de Inclusão da Pessoa com Deficiência (Estatuto da Pessoa com Deficiência). Diário Oficial da União, Brasília, DF, 7 jul. 2015. Disponível em: <http://www.planalto.gov.br/ccivil_03/_ato20152018/2015/lei/l13146.htm>. Acesso em: 2 nov. 2017.

Fundação Instituto Brasileiro de Geografia 
e Estatística. Portaria n. 4, de 28 de agosto de 2017. Diário Oficial da União, Brasília, Seção 1, 30 ago. 2017. Disponível em: $<$ http://pesquisa.in.gov.br/imprensa/jsp/visualiza/ind ex.jsp?jornal $=1 \&$ pagina $=58 \&$ data $=30 / 08 / 2017>$. Acesso em: 21 mai. 2018.

CAIADO, K. R. M. Aluno deficiente visual na escola: lembranças e depoimentos. Campinas: Autores Associados, 2006.

CENSO Demográfico 2010. Instituto Brasileiro de Geografia e Estatística. 2010. Disponível em: <https://biblioteca.ibge.gov.br/visualizacao/periodic os/94/cd_2010_religiao_deficiencia.pdf $>$. Acesso em: 21 mai. 2018.

CORTE, M. G. D.; MELLO, G. B. Cursos de licenciatura em educação especial e contextos emergentes. Revista Internacional de Educação Superior, Campinas, SP, v. 4, n. 2, p. 308-329, maio-ago. 2018.

CROCHÍK, J. L. Apontamentos sobre rede de pesquisa em educação inclusiva: uma experiência. In: MIRANDA, T. G. (Org.). Práticas de inclusão escolar: um diálogo multidisciplinar. Salvador: EDUFBA, 2016. p. 37-50. Disponível em: <https://repositorio.ufba.br/ri/bitstream/ri/22493/1/P ráticasDeInclusãoEscolar-

UmDiálogoMultidisciplinar_MIRANDA\%2C\%20T herezinha\%20Guimarães.pdf >. Acesso em: $01 \mathrm{dez}$. 2017.

CURSO 633 - Educação Especial/Diurno. Universidade Federal de Santa Maria, Santa Maria, [s.d.]. Disponível em:

http://w3.ufsm.br/edespecial/?page_id=125https:/>. Acesso em: 21 mai. 2018.

CURSOS 2018. Instituto Benjamin Constant. 2018. Disponível em:

<http://www.ibc.gov.br/component/content/article/7 9-pesquisa-e-tecnologia/producao-de-materialespecializado/476-cursos-2018>. Acesso em: 21 mai. 2018.

FUNDAÇÃO DORINA Nowill para cegos. Cursos e palestras. [s.d.] Disponível em: <http://www.ibc.gov.br/component/content/article/7 9-pesquisa-e-tecnologia/producao-de-materialespecializado/476-cursos-2018>. Acesso em: 21 mai. 2018.
GALVÃO, A.; LEAL, T. Há lugar ainda para métodos de alfabetização? Conversa com professores(as). In: MORAIS, A. G.; ALBUQUERQUE, E. B. C. de; LEAL, T. F. (Orgs.). Alfabetização: apropriação do sistema de escrita alfabética. Belo Horizonte: Autêntica, 2005.

GATTI, B. A. Formação de professores no Brasil: características e problemas. Educação e Sociedade, Campinas, v. 31, n. 113, p. 1.355-1.379, out.-dez. 2010. Disponível em: http://www.cedes.unicamp.br. Acesso em: 22 mai. 2018.

JESUS, D. M.; VIEIRA, A. B. O observatório nacional de educação especial e seus desdobramentos no estado do Espírito Santo. In: MIRANDA, T. G. (Org.). Práticas de inclusão escolar: um diálogo multidisciplinar. Salvador: EDUFBA, 2016. p. 67-88.

MASINI, E. A. F. S. Uma experiência de inclusão providências, viabilização e resultados. Educar, Curitiba, n. 23, p. 29-43, 2004. Disponível em: <http://www.scielo.br/pdf/er/n23/n23a04.pdf>. Acesso em: 01 dez. 2017.

MELETTI, S. M. F.; BUENO, J. G. O impacto das políticas públicas de escolarização de alunos com deficiência: uma análise dos indicadores sociais no Brasil. Linhas Críticas, Brasília, DF, v. 17, n. 33, p. 367-383, mai./ago. 2011.

MENDES, E. G. A radicalização do debate sobre inclusão escolar no Brasil. Revista Brasileira de Educação, v. 11, n. 33, set./dez. 2006. Disponível em:

<http://www.scielo.br/pdf/rbedu/v11n33/a02v1133. pdf $\rangle$. Acesso em: 25 nov. 2017.

NOGUEIRA, A. L. H. Concepções de "trabalho docente": as condições concretas e os discursos das prescrições oficiais. Educação e Sociedade, Campinas, v. 33, n. 121, p. 1.237-1.254, out.-dez. 2012.

NOVAES, S. C. Imagens e ciências sociais: trajetória de uma relação difícil. In: BARBOSA, A.; CUNHA, E. T. da; HIKIJI, R. S. G. (Orgs.). Imagem-conhecimento: antropologia, cinema e outros diálogos. Campinas, SP: Papirus, 2009.

OLIVEIRA, P. S; MENDES, E. G. Análise do projeto pedagógico e da grade curricular dos cursos 
de licenciatura em educação especial. Educação $e$ Pesquisa, São Paulo, v. 43, n. 1, p. 263-279, jan./mar. 2017. Disponível em: <http://dx.doi.org/10.1590/S15179702201605145723>. Acesso em: 25 nov. 2017.

PIMENTEL, S. C. O desenvolvimento de uma práxis social inclusiva: uma proposta para a transformação do cotidiano escolar. In: MIRANDA, T. G. (Org.). Práticas de inclusão escolar: um diálogo multidisciplinar. Salvador: EDUFBA, 2016. p. 11-24. Disponível em: <https://repositorio.ufba.br/ri/bitstream/ri/22493/1/P ráticasDeInclusãoEscolarUmDiálogoMultidisciplinar_MIRANDA\%2C\%20T herezinha\%20Guimarães.pdf $>$. Acesso em: $01 \mathrm{dez}$. 2017.

PORTAL do ementário. Universidade Federal de Santa Maria, Santa Maria, [s.d.]. Disponível em: $<$ https://portal.ufsm.br/ementario/disciplina.html?di sciplina=46764>. Acesso em: 21 mai. 2018.

PROJETO POLÍTICO-PEDAGÓGICO do curso de licenciatura em educação especial. Universidade Federal de São Carlos, São Carlos, 2012.

Disponível em:

<http://www.cleesp.ufscar.br/curso/projeto-politicopedagogico/view>. Acesso em: 28 mai. 2018.

REILY, L. H. Escola inclusiva: linguagem e mediação. Campinas: Papirus, 2004.

SÁ, E. D. de; CAMPOS, I. M. de; SILVA, M. B. C. (Orgs.). Formação continuada a distância de professores para o atendimento educacional especializado: deficiência visual. Brasília: SEESP/SEED/MEC, 2007.

SAVIANI, D. Formação de professores: aspectos históricos e teóricos do problema no contexto brasileiro. Revista Brasileira de Educação, v. 14, n. 40, p. 143-155, jan.-abril 2009.

SILVA, A. G.; SILVA, E. P.; OLIVEIRA, S. F. P. Vitória sobre a cegueira: a oralidade na alfabetização e no letramento de portadores de necessidades visuais. Revista Eletrônica de Letras (Online), v. 7, n. 7, ed. 7, jan.-dez. 2014. Disponível em:
$<$ http://periodicos.unifacef.com.br/index.php/rel/arti cle/view/1029/779>. Acesso em: $01 \mathrm{dez} .2017$.

UFC VAI FORMAR 3.150 professores em educação especial. Universidade Federal do Ceará - Faculdade de Educação, Fortaleza, [s.d.]. Disponível em:

$<$ http://www.faced.ufc.br/index.php?option=com_c ontent $\&$ task $=$ view $\& i d=114 \&$ itemid $=42>$. Acesso em: 27 mai. 2018.

UNESCO - ORGANIZAÇÃO DAS NAÇÕES UNIDAS PARA A EDUCAÇÃO, A CIÊNCIA E A CULTURA. Declaração mundial sobre educação para todos: satisfação das necessidades básicas de aprendizagem. Jomtien: Unesco, 1990. Disponível em:

$<$ http://unesdoc.unesco.org/images/0008/000862/08 6291por.pdf>. Acesso em: 27 abr. 2018.

UNESCO - ORGANIZAÇÃO DAS NAÇÕES UNIDAS PARA A EDUCAÇÃO, A CIÊNCIA E A CULTURA. Declaração de Salamanca sobre princípios, política e práticas na área das necessidades educativas especiais. Salamanca, 1994. Disponível em:

<http://unesdoc.unesco.org/images/0013/001393/13 9394por.pdf >. Acesso em: 27 abr. 2018.

VICTOR, S. L.; PILOTO, S. S. de F. H. Formação do professor no contexto do Observatório Nacional de Educação Especial. In: VICTOR, S. L.; OLIVEIRA, I. M. de (Orgs.). Educação Especial: políticas e formação de professores. Marília: ABPEE, 2016. p. 159-178.

VIGOTSKI, L. S. Obras completas: fundamentos de defectología. Ciudad de La Habana, Cuba: Pueblo y Educación, 1997.

VILARONGA, C. A. R; CAIADO, K. R. M. Processos de escolarização de pessoas com deficiência visual. Revista Brasileira de Educação Especial, Marília, v. 19, n. 1, p. 61-78, mar. 2013. Disponível em:

$<$ http://www.scielo.br/scielo.php?script=sci_arttext \&pid=S1413$65382013000100005 \& \operatorname{lng}=\mathrm{en} \& \mathrm{nrm}=\mathrm{iso}>$. Acesso em: 26 abr. 2018. <http://dx.doi.org/10.1590/S141365382013000100005>. 


\section{Sobre os autores}

Rosana Davanzo Batista é graduada em Pedagogia pela Universidade Metodista de Piracicaba (2009) e Doutora em Educação pela Universidade Metodista de Piracicaba (2018).

Mateus Henrique do Amaral é graduado em Letras Licenciatura em Língua Portuguesa pela Universidade Metodista de Piracicaba (2016) e Mestrando em Educação do Programa de Pós-Graduação em Educação da Universidade Metodista de Piracicaba.

Maria Inês Bacellar Monteiro é graduada em Fonoaudiologia pela Pontifícia Universidade Católica de Campinas (1978) e Doutora em Psicologia pela Universidade de São Paulo (1992). Professora aposentada, foi docente do Programa de Pós-graduação em Educação da Universidade Metodista de Piracicaba.

Recebido em julho de 2018.

Aprovado em outubro de 2018. 